\title{
Sistema para Teste de Conhecimento para Prova Teórica do DETRAN: Um estudo de aceitação do aplicativo pelos usuários
}

\author{
Andrei Carniel$^{1}$, Robison Cris Brito ${ }^{1}$, Mauricio Copetti ${ }^{1}$ \\ ${ }^{1}$ Departamento de Informática - Universidade Tecnológica Federal do Paraná (UTFPR) \\ Via do Conhecimento, Km 1 CEP 85.503-390 - Pato Branco - PR - Brazil \\ andrei.carniel@gmail.com, robison.brito@gmail.com, \\ mauriciocopetti_@hotmail.com
}

\begin{abstract}
The human being is not a static being, being in constant motion, moving from home to work, whether in holiday travel, the visiting of friends, this lifestyle is present in the daily lives of many people. With modern life and the great distances between places, especially in large cities, automobile use has become much more than a comfort, and a necessity. To be able to drive a vehicle today, candidates must pass some tests, which are tests of theory and practice. The theoretical proof is full of concepts that must be assimilated by the candidate, such as mechanics, laws, defensive driving, first aid, environment and social life. The DMV provides a means to study the Internet dedicated to computers, but not all people have access and time to be in front of a computer studying such issues. Thus, this study aims to develop and test a mobile learning environment, based on Android devices (smartphones and Tablets), where the user can study and test your knowledge anywhere, through an off-line application, which does Internet use. The results of the study are presented.
\end{abstract}

Resumo. O ser humano não é um ser estático, estando em constante movimento, seja de movendo da casa para o trabalho, seja nas viagens de férias, na visita aos amigos, este estilo de vida está presente no cotidiano de muitas pessoas. Com a vida moderna e as grandes distâncias entre os lugares, em especial nos grandes centros, o uso do automóvel se tornou muito mais do que um conforte, sendo uma necessidade. Para ser habilitado a conduzir um veículo hoje, os candidatos devem passar por algumas provas, sendo estas provas de teóricas e práticas. A prova teórica é repleta de conceitos que devem ser assimilados pelo candidato, tais como mecânica, legislação, direção defensiva, primeiros socorros, meio ambiente e convívio social. O DETRAN fornece um meio de estudo pela Internet dedicado para computadores, porém nem todas as pessoas tem acesso e tempo para ficarem na frente de um computador estudando tais questões. Assim, o presente trabalho visa desenvolver e testar um ambiente de aprendizado móvel, baseado em dispositivos Android (smartphones e Tablets), onde o usuário pode estudar e testar seus conhecimentos em qualquer lugar, por meio de um aplicativo off-line, que não faz uso da Internet. Os resultados do estudo são apresentados.

\section{Introdução}

Com o passar dos tempos a necessidade de se locomover foi se acentuando mais e mais. Hoje tem-se veículos para as mais diversas finalidades, como carro, moto, ônibus, caminhão, entre outros, tornando-os indispensáveis no dia a dia das pessoas, seja para se deslocar ao trabalho, para lazer ou mesmo utilizado para trabalho.

Cerca de $80 \%$ da população brasileira se desloca com algum tipo de veículo (IPEA, 2011), sendo que destes $44 \%$ usam o transporte público, $23.8 \%$ carros e $12.6 \%$ motocicletas, ainda pode-se destacar as pessoas que utilizam destes veículos para trabalhar, como motoristas de ônibus ou de veículos de carga.

Mesmo com os números indicando que a maioria da população utiliza o transporte público, o número de pessoas que optam por utilizar o veículo próprio é muito grande, em especial nas pequenas cidades. Segundos dados do DENATRAN (2014), a frota nacional de 
veículos no ano de 2003 era de 2.251.022 veículos, em 2013 esse número subiu para 5.394.535 veículos, ou seja, um aumento de $139 \%$.

Atualmente para conduzir qualquer veículo automotor rodoviário, há a necessidade de um condutor habilitado por um órgão competente para conduzir o veículo, este órgão é o DETRAN (2014).

No Brasil, para obter uma Carteira Nacional de Habilitação, ou $\mathrm{CNH}$, é necessário atingir a maioridade (18 anos) e passar por testes psicológicos, os quais irão avaliar se um indivíduo pode ser habilitado, frequentar curso de formação de condutores e ao final deste é realizado a prova teórica, o qual irá verificar o aprendizado do aluno.

O teste teórico verifica o conhecimento sobre mecânica, legislação, direção defensiva, primeiros socorros, meio ambiente e convívio social. Consiste em trinta perguntas, que devem ser respondidas em até cinquenta minutos. Para ser aprovado deve se conseguir $70 \%$ de acerto, ou seja, vinte e uma questões. Ao(s) aprovado(s) na prova teórica, o passo seguinte são 15 horas de aulas práticas no transito, para poder realizar a prova prática (direção) (CONTRAN, 2004).

Devido ao grande número de áreas de abrangência para que o aluno seja habilitado, o DETRAN, a fim melhorar ainda mais os níveis de aprendizado sobre o transito, disponibiliza via site um meio de estudo para que todos os candidatos possam estudar e também testar seus conhecimentos. Porém esse meio de estudo foi desenvolvido para computadores convencionais, o que torna sua utilização em dispositivos móveis um tanto complicada.

Vale lembrar que computadores convencionais não priorizam a mobilidade, logo um candidato poderá ter algumas restrições quanto ao local e hora para estudos, perdendo assim a oportunidade de estudar enquanto espera um ônibus, está na fila do banco ou entre uma atividade e outra. Neste contexto, o uso de dispositivos móveis poderia aumentar a qualidade do estudo dos candidatos, permitindo um estudo com materiais interativos (questões, simulados, etc) a qualquer momento.

Baseado nesses fatos, o foco deste trabalho disponibiliza um ambiente de estudo para a prova teórica do DETRAN para obtenção de $\mathrm{CNH}$, por meio de material interativo e questões com respostas usando dispositivos móveis.

\section{Utilização de Dispositivos Móveis no Contexto Educacional}

O Brasil é o $4^{\circ}$ maior mercado consumidor de smartphones de mundo (TOZETTO, 2014). Destes, segundo um estudo realizado pela IDC no último trimestre de $2013,88,73 \%$ dos smartphones vendidos possuíam Sistema Operacional Android, 6\% possuíam Windows Phone e 4,7\% possuíam o Sistema IOS (OLHARDIGITAL, 2014). Ainda segundo Teleco (2014), no mês de dezembro de 2013 o número de smartphones no mercado correspondia 2,5 milhões de aparelhos, contra 1,4 milhões de aparelhos celulares tradicionais, o que mostra a superioridade desta nova plataforma.

Neste contexto, empresas e instituições estão investindo no Mobile Learning, termo utilizado para o uso de conteúdo didático em dispositivos móveis.

Segundo (MARÇAL, ANDRADE, RIOS, 2005, p. 03), os objetivos de aplicações Mobile Learning são:

- Melhorar os recursos para o aprendizado do aluno, que poderá contar com um dispositivo computacional para execução de tarefas, anotação de ideias, consulta de informações via Internet, registro de fatos através de câmera digital, gravação de sons e outras funcionalidades existentes;

- Prover acesso aos conteúdos didáticos em qualquer lugar e a qualquer momento, de acordo com a conectividade do dispositivo;

- Aumentar as possibilidades de acesso ao conteúdo, incrementando e incentivando a utilização dos serviços providos pela instituição, educacional ou empresarial; 
- Expandir o corpo de professores e as estratégias de aprendizado disponíveis, através de novas tecnologias que dão suporte tanto à aprendizagem formal como à informal;

- Fornecer meios para o desenvolvimento de métodos inovadores de ensino e de treinamento, utilizando os novos recursos de computação e de mobilidade.

Um exemplo é a Fundação Vanzolini, que firmou uma parceria com escolas municipais da cidade de São Vicente (SP), onde o objetivo do projeto é incluir conteúdo didático móvel no currículo escolar do município, para que ocorra um maior interesse dos alunos, já que essa é a geração que fazem maior uso da tecnologia móvel. No entanto, muitos professores ainda têm certa dificuldade para utilizar esses recursos na sala de aula.

Em uma enquete do portal (INSTITUTO CLARO, 2011) quase metade dos educadores afirmaram querer integrar a ferramenta para dispositivos móveis à sala de aula, resultado este apresentado na Figura 1.

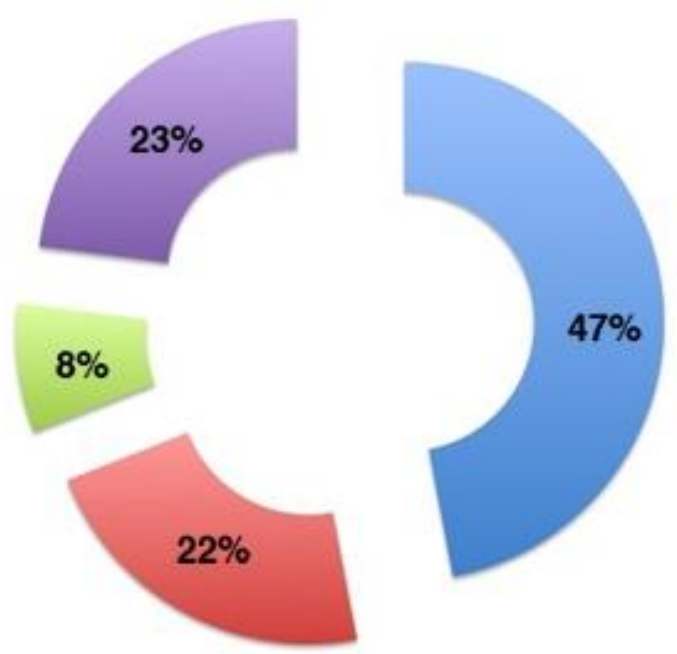

\section{Você usa o celular como ferramenta pedagógica?}

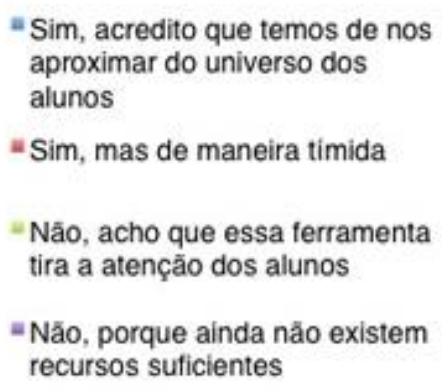

Figura 1. Recursos Pedagógicos no Celular.

Fonte: https://www.institutoclaro.org.br/em-pauta/uso-de-celulares-na-educacao-aproxima-professoresdo-universo-dos-alunos/

De acordo com a Figura 1, pode-se observar também que um número considerável de pessoas (23\%) afirma que os celulares não continham recursos pedagógicos o suficiente para seu bom aproveitamento em estudos.

\section{Trabalhos Relacionados}

Existem alguns trabalhos relacionados no mercado. O simulado teórico do site do DETRAN, o qual foi utilizado como base para o desenvolvimento do aplicativo, e é focado para computadores convencionais e não muito atrativo para a utilização em dispositivos móveis. A seguir serão mostrados alguns aplicativos parecidos disponíveis na Google Play, loja de aplicativos da Google.

DETRAN Simulados, um aplicativo simples, que disponibiliza nove simulados com trinta questões cada, caso o usuário deseje ter mais tipos de provas ele tem que baixar a versão premium, pode ser usado sem a conexão com a Internet, disponível para sistemas Android 2.3 ou superior, e baixado de 100.000 a 500.000 vezes Google Play.

Simulado DETRAN-SP, um aplicativo feito para a prova teórica do estado de São Paulo, disponibilizado apenas a funcionalidade de simulado, com trinta questões geradas aleatoriamente, mas para poder utilizar o mesmo é necessário estar conectado na Internet, disponível para sistemas Android 2.2 ou superior e iOS 6.1 ou posterior, e também baixado de 100.000 a 500.000 vezes na Google Play. 
Simulado DETRAN RJ, aplicativo desenvolvido por Lucas R. Martins, feito para a prova teórica do Rio de Janeiro, pode ser utilizado sem conexão com a Internet, disponível para aplicativos com Android 2.2 ou superior e baixado de 50.000 a 100.000 vezes

O mais importante é que todos esses aplicativos citados anteriormente tiveram uma avaliação positiva, ambos conseguiram uma nota 4.0 de 5 ou superior, com cerca de 5000 avaliações, e a maioria dos comentários foram positivos, destacando a importância que os dispositivos móveis estão ganhando no mercado.

\section{Primeira Habilitação}

A primeira habilitação é vista por muitas pessoas um grande desafio, dado o grande número de horas aulas e a complexidade das provas.

Para uma pessoa conseguir a primeira habilitação, é necessário passar pelas seguintes etapas: ser penalmente imputável, saber ler e escrever, possuir documento de identidade e $\mathrm{CPF}$, deve estar cadastrado no RENACH, ser aprovado na Avaliação Psicológica, ser aprovado no exame. Aptidão Física e Mental, realizar o curso Teórico-técnico, ser aprovado no exame Teórico-técnico, realizar o curso de Prática de Direção Veicular e ser aprovado no exame de Pratica de Direção Veicular, nesta ordem. (CONTRAN, 2004).

Antes de realizar a prova teórica o candidato deve frequentar 30 horas de aulas teóricas, sendo elas 12 horas sobre legislação, 8 horas direção defensiva, 4 horas primeiros socorros, 4 horas de noção de proteção e respeito ao meio ambiente e de convívio social, e por fim 2 horas sobre funcionamento de veículos de 2 e 4 rodas.

Já o processo de reciclagem ocorre quando o condutor já possui a habilitação e perde ela devido ao fato de ter cometido infrações de trânsito. Esse processo é muito semelhante ao processo da primeira habilitação, onde o candidato deverá passar por todos os exames necessários para a habilitação na categoria desejada e participar do curso teórico, que pode ser executado de em duas modalidades diferentes, são elas: presencial e não presencial. Em ambas as modalidades o candidato deverá participar do curso 30 horas aula teóricas, sendo: Legislação de transito (12 horas aulas), direção defensiva (8 horas aulas), primeiros socorros (4 horas aulas) e relacionamento interpessoal (6 horas aulas). E após, submeter-se novamente a prova teórica nas mesmas condições da primeira habilitação.

Em ambos os casos, $1^{\circ}$ habilitação ou reciclagem, o candidato deverá estudar e passar novamente pela prova teórica, vale lembrar que as provas são geradas aleatoriamente a partir de um mesmo banco de dados do DETRAN. É considerado apto o candidato se obtiver aproveitamento mínimo de $70 \%$ nessa prova.

\section{Metodologia}

O desenvolvimento do Software para Teste de Conhecimento para a Prova Teórica do DETRAN foi dividido em etapas, seguindo o modelo sequencial linear de Pressman (2006). Essas etapas são:

a) Requisitos: Os requisitos para o desenvolvimento deste sistema foram criados conforme necessidades pessoais do programador, desta forma, não foi realizado um levantamento formal dos requisitos para o desenvolvimento do sistema.

b) Análise: $O$ caso de uso descreve o cenário que mostra as funcionalidades do aplicativo, para o qual seria proposto uma solução. Os casos de uso serão criados utilizando a ferramenta Astah Community, para produzir o diagrama UML.

c) Projeto: Nesta fase seria criado um diagrama de classe utilizando a linguagem UML, mas devido à complexidade do projeto, será apresentado uma figura com a estrutura do código fonte desenvolvido. 
d) Desenvolvimento: $O$ desenvolvimento será realizado utilizando as tecnologias: Java SE na versão 1.7.0_15-b03; ADT Bundle 22.3.0, com seus respectivos softwares, IDE Eclipse, Android SDK 4.0.3 (API 15) e o Android AVD também na versão 15 da API.

e) Teste: Testes são necessários para garantir o funcionamento esperado do aplicativo criado. Foi feito de 3 maneiras diferentes: A primeira foi diretamente no Android AVD, através da máquina virtual foi elaborado as primeiras versões e efetuado os primeiros testes; Após instalado em um smartphone convencional onde foi verificado a interface e usabilidade; E por fim a instalação em um tablet, já que muitos desses dispositivos também são compatíveis com o software produzido.

f) Implantação: Consistiu em utilizar 2 dispositivos móveis, um smartphone e um tablet, e implementado o estudo de aceitação para com os usuários nos dois dispositivos.

\section{Sistema}

O software foi desenvolvido com base no teste teórico disponível no site do DETRAN-PR (SIMULADO, 2014), porém com o foco no mercado de dispositivos móveis, os quais nos fornecem grande mobilidade e acessibilidade.

No quesito mobilidade, o software possui 83 questões retiradas diretamente no site do DETRAN, salvas em um banco de dados off-line, permitindo assim que o usuário consiga estudar em qualquer lugar, sem necessitar de uma conexão com a Internet, o que deixar o aplicativo mais próximo do teste real, ao mesmo tempo que facilita o uso do aplicativo em um ônibus, tempos de intervalo no trabalho, ou em locais com dificuldade de acesso à Internet ou rede da operadora. E também pela facilidade de levar o dispositivo a qualquer lugar, ser ter a necessidade de recarrega-lo em curtos períodos de tempo.

Já no quesito acessibilidade foi optado pelo sistema Android, o qual está dominando o atual mercado de smartphones ao mesmo tempo que oferece dispositivos com boa capacidade de processamento (algumas vezes se igualando aos computadores convencionais), facilitando a utilização do software nos mais diversos aparelhos disponíveis no mercado. E ainda utilizando uma interface de simples e de fácil utilização, exibindo somente as informações necessárias ao estudo e testes, evitando que uma determinada faixa de público seja priorizada, e sim a maior a maior parte dele.

O software é composto por dois módulos principais: o modo estudo e o modo simulado. Ambos recuperam 30 perguntas aleatoriamente do banco de dados do celular, e exibem uma a uma na tela do aplicativo, juntamente com o recurso de navegação, o que permite o usuário responder as perguntas na hora que desejar e ainda alterar quantas vezes achar necessário.

O modo estudo, Figura 2 (A), prioriza o estudo e entendimento da questão, por isso não há limite de tempo nesse módulo. Será exibida uma pergunta por tela juntamente com as opções de resposta, botões de navegação, caso o usuário não deseje responder a pergunta no momento ou ainda queira voltar e ver novamente a pergunta, e a opção finalizar. Assim que uma opção de resposta é selecionada o software automaticamente marca a resposta correta com fundo verde, independentemente do usuário de ter errado ou acertado a questão. No momento que o usuário seleciona a opção finalizar é redirecionado a uma tela que irá mostrar o número de acertos juntamente com o tempo gasto no modo estudo.

O modo simulado, Figura 2 (B), é muito parecido com a tela de estudo, será exibida uma pergunta por vez juntamente com as respectivas opções de respostas, opções de navegação entre perguntas e finalizar para encerrar a prova e exibir o número de acertos e tempo restante que o usuário possuía até clicar no botão finalizar. Como o modo simulado tem foco na simulação das condições reais da prova teórica aplicada pelo DETRAN, possui 2 divergências em relação a tela de estudo, o tempo limite e não exibe a resposta certa. 
O tempo limite é o mesmo do dia da prova teórica, máximo de 50 minutos, é exibido na forma de um contador regressivo, ao final do tempo limite se a prova ainda não for finalizada será automaticamente encerrado e irá redirecionar o usuário a tela de resultados, Figura 2 (C), onde será exibido apenas o número de acertos, a informação se passou e o tempo que sobrou. É importante destacar que no dia de realização da prova do DETRAN o candidato não pode visualizar os acertos e erros de sua prova no dispositivo no final da prova, cabendo ao fiscal de sala decidir se irá ou não imprimir uma folha com o resultado.

Se o usuário clicar no botão Menu Principal ele vai ser redirecionado para a tela inicial a qual contém o menu de instruções seguido dos botões de Estudo, Simulado e a opção Sair.

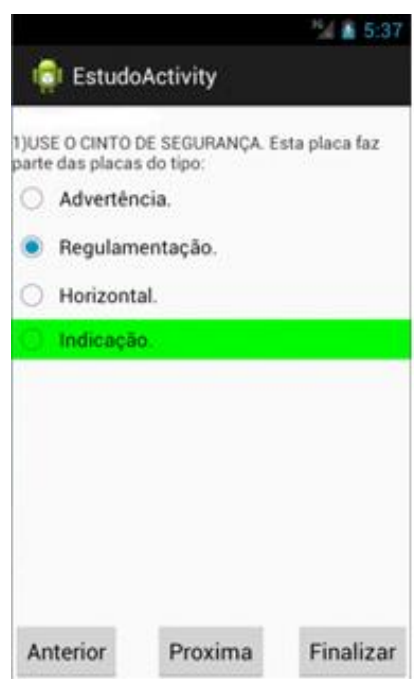

(A)

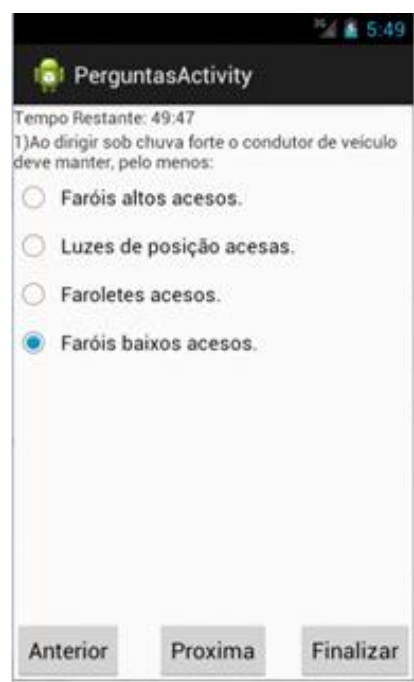

(B)

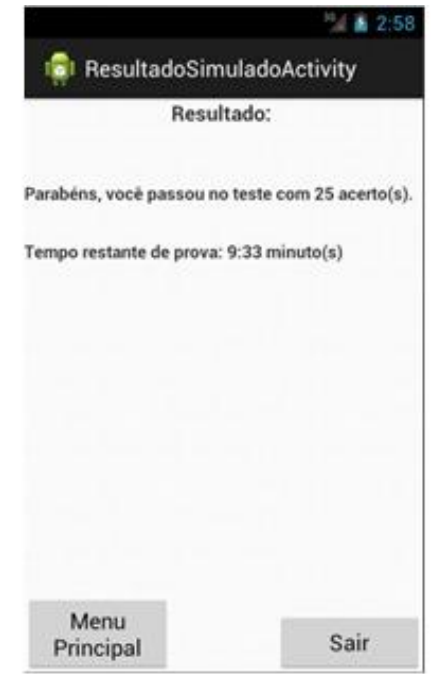

(C)

Figura 2. (A) Módulo estudo, (B) módulo simulado e (C) tela de resultado do modo simulado.

Como o banco de dados é o mesmo para a prova da primeira habilitação e reciclagem o software pode ser utilizado em ambos os casos sem a necessidade de nenhuma alteração.

\section{Pesquisa com usuários}

Para a pesquisa com os usuários foi utilizado dois dispositivos móveis, um smartphone convencional e um tablet. Primeiramente era exibida aos voluntários o método de estudo disponível no site do DETRAN-PR e após entregue os dispositivos móveis com o software rodando, para que posteriormente respondessem a pesquisa de aceitação. O objetivo geral dessa pesquisa era efetuar um comparativo entre a tecnologia disponível para computadores convencionais e a proposta para utilização de um software para dispositivos móveis.

Uma amostra de 34 voluntários, sendo $67,6 \%$ do gênero feminino e 32,3\% do gênero masculino, com idade média de 24,9 anos, variando de 18 a 56 anos participaram do estudo. No momento desse levantamento, cerca de $56 \%$ dos participantes do estudo realizavam um curso no centro de formação de condutores para obter a primeira habilitação para condução de veículos automotores. O tempo médio de duração da interação dos participantes com o software foi de 10 minutos, sendo que em alguns casos os participantes utilizavam o software por mais de uma vez para medir seus conhecimentos.

Vários questionamentos foram feitos, para caracterização do estudo. A primeira pergunta foi a respeito da opinião dos voluntários sobre o software ter sido desenvolvido para dispositivos móveis. As opções eram "Muito Bom", "Bom", "Indiferente", "Regular" e "Ruim". 82\% caracterizaram o software como "Muito Bom", 15\% como "Bom" e 3\% "Indiferente". Sendo que vários elogios foram recebidos pelos voluntários devido a facilidade/disponibilidade de possuir um smartphone ou tablet (Figura 3). 


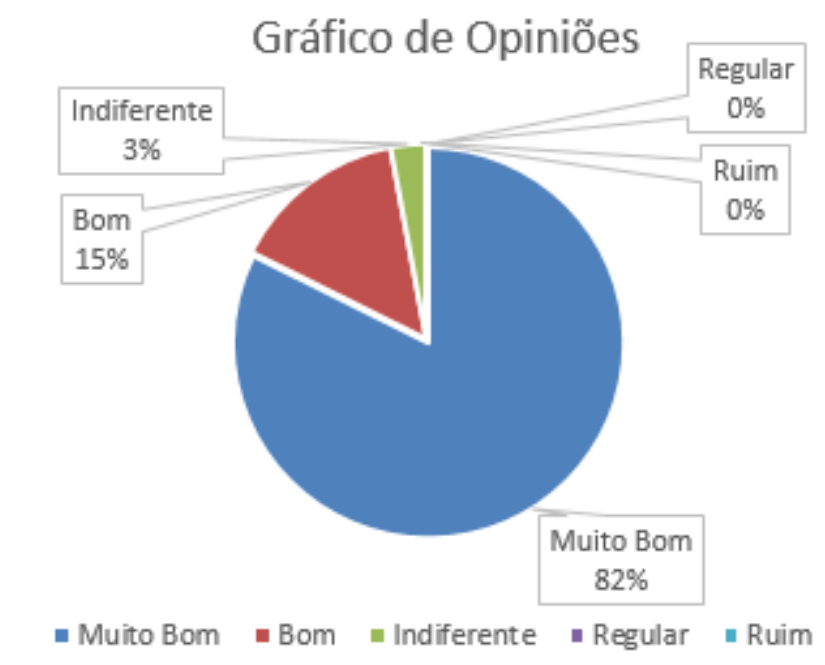

Figura 3. Gráfico de Opiniões

Outras 3 perguntas foram feitas instruindo os voluntários para que levassem em consideração o tempo disponível no dia a dia para estudo do teste teórico.

A primeira questão foi considerando o auxílio que o software possibilitava de forma geral, ou seja, considerando desde o tempo livre em casa para estudar bem como em situações mais complexas, dentro de um ônibus, pequenos intervalos, etc. Como resposta o voluntário deveria atribuir em uma escala de 0 a 10, sendo 0 como nenhum auxílio e 10 como total auxílio, o quanto o software iria lhe ajudar. $47 \%$ qualificou com escala 10, 38\% qualificou com escala 9, sendo a menor escala atribuída a $6(3 \%)$. Isso demonstra que os voluntários acreditam que o software para dispositivos móveis seria mais útil que o software para computadores convencionais.

Quando questionados sobre o melhor aproveitamento do tempo comparando o uso do software com o de livros e apostilas, considerando a hipótese que os voluntários já possuísse o conhecimento teórico necessário ou que estivessem cursando as aulas teóricas. Como resposta o voluntário deveria atribuir em uma escala de 0 a 10 , sendo 0 como nenhum aproveitamento e 10 como total aproveitamento. Novamente o software para dispositivo móvel obteve as melhores qualificações, sendo $47 \%$ das qualificações para escala 10, 32\% para a escala 9, $18 \%$ para a escala 8 e $3 \%$ para escala 7 . Nesse caso pode ser claramente observado a preferência dos voluntários por dispositivos móveis aos métodos convencionais, que é considerado mais demorado.

Os voluntários também foram questionados quanto a praticidade de se utilizar um smartphone ou tablet como forma de estudo e/ou testes do seu conhecimento, considerando as mais diversas situações possíveis. Como resposta o voluntário deveria atribuir em uma escala de 0 a 10, sendo 0 como nada prático e 10 como totalmente prático. As qualificações foram: $79 \%$ escala $10,15 \%$ escala $9,3 \%$ escala 8 e $3 \%$ escala 7 . De acordo com as respostas, fica evidente que é muito mais prático utilizar um dispositivo móvel a outros. Essa questão levantou muitos debates, dentre eles, a grande capacidade de informações que pode-se levar em um dispositivo do gênero, facilidade transporte, tempo utilização, facilidade de uso e busca de informações através destes dispositivos, entre outros. E também pode-se concluir a atual sociedade está mais habituada para a informatização de informações.

Por fim, foi analisado a escola da plataforma para testes, o Android. Devido ao fato que existem outras plataformas disponíveis no mercado para dispositivos móveis, como o Windows Phone e IOS. Como resposta o voluntário deveria atribuir em uma escala de 0 a 10 , sendo 0 como pior escolha de plataforma e 10 como a melhor escolha de plataforma. $68 \%$ das qualificações foi para a escala $10,23 \%$ para a escala $9,6 \%$ para a escala 8 , e $3 \%$ para a escala 
6. Lembrando que grande parte dos smartphones vendidos possuem Android, que atualmente no Brasil possui a preferência do público.

\section{Conclusão}

Aprendizado com dispositivos ainda é um tema novo, mas com grande potencial de crescimento para as mais diversas áreas. Dessa forma temos de aproveitar o máximo possível da aceitação do público e da informatização da sociedade para deixar a transição a mais suave possível. Vale destacar que esses dois fatores podem, também, acelerar o processo, o que pode ser considerada uma boa estratégia para auxiliar na informatização da sociedade e divulgação de informações.

Neste trabalho foi apresentado um estudo sobre utilização de dispositivos móveis no método de aprendizado e testes, com foco na opinião do público sobre a aceitação da solução proposta, baseado no teste teórico do DETRAN, o qual foi desenvolvido para computadores convencionais que possuem conexão com a Internet.

O software foi desenvolvido de forma a oferecer um modo de estudo e um de simulação de prova, a possíveis candidatos a serem habilitados quanto para os candidatos a reciclagem de carteira.

O estudo sobre utilização de dispositivos móveis teve uma análise. Durante a pesquisa foi possível notar um grande desejo de informatização por parte dos voluntários, houve vários questionamentos também a respeito sobre como seria feita a transição e principalmente quando estaria disponível para download.

A ideia foi muito bem aceita pelo público, e após as pesquisas muitos voluntários ficaram conversando a respeito do software e quando eram questionados do motivo de terem apreciado a solução proposta, a principal resposta era pelo fato do software ter sido desenvolvido para um dispositivo móvel, os qual já estão habituados a usar no dia a dia, da grande capacidade de armazenamento de informação e uma excelente capacidade de conectividade com a Internet nos mais diversos locais, bateria com uma boa capacidade de utilização e principalmente pelo grande número de funcionalidades que um dispositivo do gênero pode ter com os mais diversos softwares disponíveis no mercado.

Como trabalhos futuros pretende-se desenvolver um módulo de estudo/simulado seletivo, onde o usuário irá escolher o conteúdo que deseja utilizar bem como o número de perguntas relacionadas a cada conteúdo. Outra proposta é o desenvolvimento do modo cliente e o modo servidor, para que o software converse diretamente com um determinado servidor para conseguir acesso a um banco de dados ainda maior de perguntas, e também apresentar como um possível candidato a substituição da atual solução utilizada pelo DETRAN.

Como trabalhos futuros para estudos do aprendizado com dispositivos moveis, pretende-se desenvolver um método de aprendizagem a distância. Onde o aluno terá um sistema semelhante a um sistema acadêmico convencional, com suas matérias, conteúdos, atividades, provas e seus respectivos professores para orientar os alunos até mesmo fora da sala de aula, mas principalmente para a utilização dentro da sala como meio para divulgação de informações entre professores e alunos de assuntos pertinentes as matérias a qual o aluno participa. Tudo isso usando dispositivos móveis.

\section{Referências}

BATTAIOLA, L. et al. Desenvolvimento de um Software Educacional com Base em Conceitos de Jogos de Computador. In: Anais do XIII Simpósio Brasileiro de Informática na Educação (SBIE), São Leopoldo: SBC, 2002. 
CONTRAN, 2004. Resolução $\mathrm{N}^{\circ}$ 168, de 14 de Dezembro de 2004. Disponível em: http://www.denatran.gov.br/download/Resolucoes/RESOLUCAO_CONTRAN_168.pdf. Acessado em: 13/07/2014.

DENATRAN, 2014. Frota de Veículos. Disponível em: http://www.denatran.gov.br/frota.htm. Acessado em: 12/09/2014.

DETRAN, 2014. Disponível em: http://www.detran.pr.gov.br/. Acessado em: 12/09/2014.

INSTITUTO CLARO, 2011. Uso de Celulares na Educação Aproxima Professores de Alunos. Disponível em: https://www.institutoclaro.org.br/em-pauta/uso-de-celulares-na-educacaoaproxima-professores-do-universo-dos-alunos/. Acessado em: 10/09/14.

IPEA, 2011. Agância Brasil - On Line: Cerca de 45\% dos brasileiros usam ônibus para se locomover. Disponível em:

http://www.ipea.gov.br/portal/index.php?option=com_content\&view=article\&id=6943\&catid $=159 \&$ Itemid=75. Acessado em: 11/07/2014.

MARÇAL, Edgar; ANDRADE, Rossana; RIOS, Riverson. Aprendizagem utilizando dispositivos móveis com sistemas de realidade virtual. Novas Tecnologias na Educação, Porto Alegre, V.3, N. 1, Maio 2005. Disponível em: http://lumenagencia.com.br/dcr/arquivos/a51_realidadevirtual_revisado.pdf. Acesso em: 10/09/14.

OLHARDIGITAL. Windows Phone deixa iOS para trás no Brasil. Disponível em: http://olhardigital.uol.com.br/pro/noticia/40338/40338. Acessado em: 12/09/2014.

PRESSMAN, Roger S. Engenharia de Software. 6 $6^{\text {a }}$ Edição. São Paulo: McGraw-Hill do Brasil, 2006.

SILVA, H. F. A., Santos, O. L.; Rafalski, J. P.; Cury, D., Menezes, C. S. Click e Ação: Um Ambiente para a Construção Colaborativa de Micromundo. In: Anais do 23 SBIE, 2012.

SIMULADO. Simulador de Provas Detran. Disponível em: http://www.simulado.detran.pr.gov.br/detran-prova/simularProva.do?action=iniciarProcesso. Acessado em: 12/09/2014.

TELECO. Vendas de Telefone Celular e Smartphone no Brasil (IDC e Abinee). Disponível em: http://www.teleco.com.br/celprod.asp. Acessado em: 12/09/2014.

TOZETTO, Claudia. Windows Phone supera iOS e assume segunda posição entre smartphones no Brasil. Disponível em: http://veja.abril.com.br/noticia/vida-digital/windowsphone-supera-ios-e-assume-segunda-posicao-no-brasil. Acessado em: Acessado em: $12 / 09 / 2014$.

VALENTE, José Armando. Diferentes usos do computador na educação. Computadores e conhecimento: repensando a educação. São Paulo: NIED, 1993. 